\title{
Placental growth factor supports neuroendocrine tumor growth and predicts disease prognosis in patients
}

\author{
Georg Hilfenhaus $^{1,2}$, Andreas Göhrig ${ }^{1,2}$, Ulrich-Frank Pape ${ }^{2}$, Tabea Neumann ${ }^{2}$, \\ Henning Jann ${ }^{2}$, Dietmar Zdunek ${ }^{3}$, Georg Hess ${ }^{3}$, Jean Marie Stassen ${ }^{4}$, \\ Bertram Wiedenmann ${ }^{2}$, Katharina Detjen ${ }^{1,2}$, Marianne Pavel ${ }^{2, *}$ and \\ Christian Fischer ${ }^{1,2, *}$ \\ ${ }^{1}$ Experimental and Clinical Research Center, a joint cooperation between the Charité Medical Faculty and the \\ Max-Delbrück Center for Molecular Medicine, Lindenberger Weg 80, 13125 Berlin, Germany \\ ${ }^{2}$ Medizinische Klinik mit Schwerpunkt Hepatologie und Gastroenterologie, Charité-Universitätsmedizin Berlin, \\ Campus Virchow-Klinikum, Augustenburger Platz 1, 13353 Berlin, Germany \\ ${ }^{3}$ Roche Diagnostics, Nonnenwald 2, 82377 Penzberg, Germany \\ ${ }^{4}$ ThromboGenics NV, Gaston Geenslaan 1, 3001 Leuven, Belgium \\ *(M Pavel and C Fischer contributed equally to this work)
}

\author{
Correspondence \\ should be addressed \\ to $C$ Fischer \\ Email \\ christian.fischer@charite.de
}

\begin{abstract}
Placental growth factor (PIGF), a VEGF-homolog implicated in tumor angiogenesis and adaptation to antiangiogenic therapy, is emerging as candidate target in malignancies. Here, we addressed the expression, function, and prognostic value of PIGF in neuroendocrine tumors (NETs). PIGF was determined in NET patients' sera collected retrospectively $(n=88)$ and prospectively $(n=87)$ using Roche-Elecsys and correlated with clinicopathological data. Tumoral PIGF was evaluated by immunohistochemistry, effects of PIGF on proliferation and migration in vitro were assessed using different NET cell lines and effects on tumor growth in vivo in orthotopic xenografts. Circulating and tumoral PIGF was elevated in patients with pancreatic NETs (pNETs) compared with control sera and respective healthy tissue. De novo PIGF expression occurred primarily in the tumor stroma, suggesting paracrine stimulatory circuits. Indeed, PIGF enhanced NET proliferation and migration in vitro and, conversely, neutralizing antibodies to PIGF reduced tumor growth in vivo. Elevated circulating PIGF levels in NET patients correlated with advanced tumor grading and were associated with reduced tumor-related survival in pNETs. Subsequent determinations confirmed and extended our observation of elevated PIGF levels in a prospective cohort of grade 1 and grade 2 pNETs $(n=30)$ and intestinal NETs $(n=57)$. In low-grade pNETs, normal circulating PIGF levels were associated with better survival. In intestinal NETs, circulating PIGF above median emerged as an independent prognostic factor for shorter time-to-progression in multivariate analyses. These data assign to PIGF a novel function in the pathobiology of NETs and propose PIGF as a prognostic parameter and therapeutic target.
\end{abstract}

\section{Key Words}

- neuroendocrine tumor

- NET

- placental growth factor

- PIGF

- prognostic biomarker http://erc.endocrinology-journals.org DOI: 10.1530/ERC-12-0223 (c) 2013 Society for Endocrinology Printed in Great Britain
Published by Bioscientifica Ltd
Endocrine-Related Cancer (2013) 20, 305-319 


\section{Introduction}

Neuroendocrine tumors (NETs) are rare neoplasms with an estimated annual incidence of $2-5 / 100000$, and are typically diagnosed at an advanced/metastatic stage of the disease. Despite dissemination however, the clinical course is relatively variable, including periods of stable disease (Baudin 2007, Modlin et al. 2008). Pancreatic NETs (pNETs) and intestinal NETs constitute distinct molecular, pathologic, and clinical subgroups, and consequently different diagnostic and therapeutic algorithms have been developed. Parameters such as tumor size, locoregional or distant metastasis, and Ki67-based grading are currently used to separate prognostic subgroups (Pape et al. 2008), but the individual course of the disease remains difficult to predict. Eventually, the majority of NET patients will experience disease progression despite therapeutic interventions, resulting in an overall 5-year survival of 30-65\% (Modlin et al. 2008, Pape et al. 2008, Panzuto et al. 2011). Hence, advanced NETs constitute a malignant disease with unsolved diagnostic and therapeutic medical needs. Recently, two targeted therapies, the tyrosine-kinase inhibitor sunitinib and the mTOR inhibitor everolimus, have been shown to be effective in prolonging progressionfree survival in both pNETs and intestinal NETs, and have been approved for treatment of pNETs (Pavel et al. 2011, Raymond et al. 2011, Yao et al. 2011b). Both drugs act at least in part via inhibition of tumor angiogenesis, promoting interest in the vascular features of NETs (Alexandraki \& Kaltsas 2012). Well-established angiogenic growth factors, such as VEGF-A (Terris et al. 1998) or angiopoietins (Srirajaskanthan et al. 2009, Detjen et al. 2010), are present in NETs. In addition, characteristic neuroendocrine secretion products, including chromogranin A fragments (Corti 2010) and serotonin (Asada et al. 2009), affect angiogenesis and vascular permeability, altogether creating a unique stromal microenvironment.

Placental growth factor (PlGF) is an angiogenic growth factor of the VEGF family, which might be important in NETs for several reasons: PlGF selectively supports pathological angiogenesis, thereby promoting tumor growth, progression, and dissemination (Carmeliet et al. 2001, Fischer et al. 2007). Thus, PlGF expression in tumor tissue and/or circulating PlGF levels correlated with tumor stage, vascularity, metastasis, survival, and recurrence in several human malignancies (Parr et al. 2005, Wei et al. 2005, 2009, Fischer et al. 2008, Maae et al. 2012). Moreover, PIGF induction occurred as a result of antiangiogenic therapies in human cancer patients and in mouse models, and (in the latter situation) constituted a functionally relevant mechanism of resistance development (Batchelor et al. 2007, Fischer et al. 2007, 2008, Rini et al. 2008, Willett et al. 2009). Finally, changes in circulating PlGF following treatment initiation are emerging as predictors of therapy response for selected antiangiogenic treatment modalities in clinical trials (Bass et al. 2010). With regard to NETs, preliminary data released from biomarker determinations in the RADIANT3 trial revealed a small transient reduction of pretreatment circulating PlGF in patients receiving everolimus (ESMO abstract Yao et al. (2011c)). Though preliminary, this observation highlights the demand for a systematic study of PlGF function in NETs.

Mechanistically, PlGF functions as a pleiotropic cytokine that is expressed by and affects a wide range of different cell types within the tumor microenvironment. PlGF binds to Flt1 (VEGFR1), and to neuropilin-1 (NRP1) and -2 (NRP2), but not to the prototype VEGF receptor Flk1 (VEGFR2) (Fischer et al. 2008). Thereby, PlGF stimulates endothelial cell migration, growth and survival, and increases the proliferation of cancer-associated fibroblasts and smooth-muscle cells (Fischer et al. 2008). Moreover, PIGF recruits endothelial and other angiogenesis-competent bone-marrow progenitors as well as tumor-associated macrophages, which promote tumor angiogenesis, growth, and metastasis (Lyden et al. 2001, Fischer et al. 2008). Besides, PlGF also directly affects tumor cells, which express the PlGF receptors Flt1, NRP1, or NRP2 (Fischer et al. 2008, Bagri et al. 2009). Thereby, PlGF can activate AKT and ERKmediated canonical signaling pathways, ultimately leading to enhanced tumor cell survival, proliferation, migration, and invasiveness (Fischer et al. 2008). Conversely, blocking PlGF using anti-PIGF antibodies emerged as therapeutic strategy to inhibit growth and metastasis in various preclinical tumor models (Fischer et al. 2007, Coenegrachts et al. 2010, Van de Veire et al. 2010, Schmidt et al. 2011, Yao et al. 2011a, Heindryckx et al. 2012).

Here, we addressed the role of PlGF in NETs. The study characterizes PlGF as a growth factor that promotes proliferation and migration of NET cells in vitro and tumor growth in vivo, and furthermore proposes circulating PlGF as a prognostic biomarker.

\section{Materials and methods}

\section{Patients and samples}

Sera and tissue samples were obtained from individuals with NETs treated at Charité-Universitätsmedizin Berlin,

Published by Bioscientifica Ltd. 
Department of Gastroenterology, from 1998 to 2012. Tumor staging with TNM classification performed at the time of blood sampling, as well as histopathological diagnosis and grading, obtained from pathology reports, were established according to ENETS guidelines (Rindi et al. 2006, 2007). Clinical parameters were obtained from systematic review of the medical records. Patient informed consent and local ethics committee approval was obtained.

A retrospective cohort of patients with pNETs $(n=88)$ and a prospective cohort including also intestinal NETs (57 intestinal NETs, 30 pNETs; Table 1) were studied. In the retrospective cohort, 65 out of 88 patients were chemotherapy-naïve and five patients were off treatment for at least 3 months before blood sampling. Out of 65,10 chemotherapy-naïve patients received somatostatin analogs (SSA), one patient had undergone radioreceptor therapy 4 months before blood sampling, and one patient had undergone transarterial chemoembolization (TACE) within a month of blood sampling. Of the pNET patients in the validation cohort, 15 were therapy-naïve, six received SSA, seven had had chemotherapy, one patient had a combination of SSA and chemotherapy, and one patient received everolimus. Out of 57, 33 intestinal NET patients were treated with SSA and one patient with a combination of SSA and everolimus. Furthermore, one patient each received everolimus, IFN $\alpha$, and the study drug oral angiogenesis inhibitor PTK787/ZK 222584 (PTK/ZK) in the intestinal NET cohort, and one patient received chemotherapy. All intestinal NET patients

Table 1 Patients baseline characteristics.

\begin{tabular}{|c|c|}
\hline \multirow[b]{2}{*}{ Parameters } & \multirow{2}{*}{$\begin{array}{c}\text { Retrospective cohort }(n=88) \\
\operatorname{pNET}(n=88)\end{array}$} \\
\hline & \\
\hline Sex (female/male) & $37 / 51$ \\
\hline Age, median (range) & $61(24-84)$ years \\
\hline \multicolumn{2}{|l|}{ pNET subtype } \\
\hline Nonfunctional & 82 \\
\hline Gastrinoma & 3 \\
\hline Insulinoma & 1 \\
\hline Glucagonoma & 1 \\
\hline VIPoma & 1 \\
\hline Carcinoid syndrome & 0 \\
\hline \multicolumn{2}{|l|}{ Midgut NET subtype } \\
\hline \multicolumn{2}{|l|}{ Lower jejunum/ileum } \\
\hline \multicolumn{2}{|l|}{ Appendix } \\
\hline \multicolumn{2}{|l|}{ Caecum } \\
\hline \multicolumn{2}{|l|}{ TNM-stage } \\
\hline Stage I & 2 \\
\hline Stage II (A/B) & $2(0 / 2)$ \\
\hline Stage III (A/B) & $8(2 / 6)$ \\
\hline Stage IV & 72 \\
\hline \multicolumn{2}{|l|}{ Grading } \\
\hline G1 & 11 \\
\hline $\mathrm{G} 2$ & 47 \\
\hline G3 & 16 \\
\hline \multicolumn{2}{|l|}{ Ki67 sub-division G2 } \\
\hline $2-5 \%$ & 15 \\
\hline$>5-10 \%$ & 14 \\
\hline$>10-15 \%$ & 4 \\
\hline$>15-20 \%$ & 7 \\
\hline \multicolumn{2}{|l|}{ PIGF levels (pg/ml) } \\
\hline Median & 19.51 \\
\hline Range & $7.27-75.09$ \\
\hline \multicolumn{2}{|l|}{ sFlt1 levels (pg/ml) } \\
\hline Median & 83.62 \\
\hline Range & $32.60-245.60$ \\
\hline \multicolumn{2}{|l|}{ PIGF:sFlt1 ratio } \\
\hline Median & 0.22 \\
\hline Range & $0.07-0.99$ \\
\hline
\end{tabular}

\begin{tabular}{|c|c|}
\hline \multicolumn{2}{|c|}{ Prospective cohort $(n=87)$} \\
\hline $\operatorname{pNET}(n=30)$ & Intestinal NET $(n=57)$ \\
\hline $\begin{array}{c}16 / 14 \\
54(30-82) \text { years }\end{array}$ & $\begin{array}{c}32 / 25 \\
59(20-78) \text { years }\end{array}$ \\
\hline $\begin{array}{c}25 \\
1 \\
1 \\
1 \\
2\end{array}$ & \\
\hline 0 & $\begin{array}{c}41 \\
52 \\
1 \\
4\end{array}$ \\
\hline $\begin{array}{c}0 \\
0 \\
3(0 / 3) \\
27\end{array}$ & $\begin{array}{c}0 \\
0 \\
1(0 / 1) \\
56\end{array}$ \\
\hline $\begin{array}{c}7 \\
23 \\
0\end{array}$ & $\begin{array}{c}30 \\
27 \\
0\end{array}$ \\
\hline $\begin{array}{c}12 \\
7 \\
3 \\
1\end{array}$ & $\begin{array}{c}20 \\
4 \\
0 \\
1\end{array}$ \\
\hline $\begin{array}{c}16.53 \\
5.79-44.05\end{array}$ & $\begin{array}{c}17.57 \\
9.80-100.91\end{array}$ \\
\hline $\begin{array}{c}85.40 \\
13.6-159.00\end{array}$ & $\begin{array}{c}80.40 \\
48.10-155.60\end{array}$ \\
\hline $\begin{array}{c}0.19 \\
0.07-1.00\end{array}$ & $\begin{array}{c}0.23 \\
0.13-0.66\end{array}$ \\
\hline
\end{tabular}

Unless otherwise stated values indicate numbers $(n)$ of subjects.

http://erc.endocrinology-journals.org DOI: $10.1530 /$ ERC-12-0223
(C) 2013 Society for Endocrinology Printed in Great Britain 
included in time-to-progression (TTP) analyses were chemotherapy-naïve. The time frame of the prospective cohort was May 2009-December 2012, and blood sampling and follow-up visits with imaging studies were performed every 3-6 months. Tumor progression was determined based on multi-phasic computed tomography or magnetic resonance imaging. Healthy controls were blood donors without medical history of malignant disease and consisted of 58 women and 29 men, with a median age of 45 years (range $41-56$ years).

\section{Materials}

Antibodies were from ReliaTech (Braunschweig, Germany; to PlGF). Secondary antibodies were from Dianova (Hamburg, Germany). Recombinant human PIGF was from R\&D Systems (Minneapolis, MN, USA). Everolimus and sunitinib were obtained from Sigma-Aldrich. Neutralizing antibodies to murine PlGF (5D11D4) and to human PlGF (16D3), as well as the IgG $_{1}$ control antibody (1C8) for use in vivo were supplied by ThromboGenics NV (Leuven, Belgium) (Fischer et al. 2007).

\section{Cell lines and culture}

BON cells were a generous gift from C M Townsend (Department of Surgery, University of Texas Medical Branch, Galveston). KRJ-I intestinal NET cells were generated by R Pfragner (Institute of Pathophysiology and Immunology, Medical University of Graz, Austria) (Pfragner et al. 1996) and kindly provided by I Modlin (Department of Surgery, Yale University School of Medicine, New Haven). BON and KRJ-I cells were authenticated by short tandem repeat DNA-typing and confirmed as unique cell lines. QGP-1 cells were from the Health Science Research Resources Bank (Osaka, Japan); H727 cells were from Banca Biologica, Istituto Nazionale per la Ricerca sul Cancro (Genova, Italy).

\section{Determination of PIGF and sFlt1 levels in serum and culture supernatants}

Concentrations of PlGF and sFlt1 were determined from frozen serum samples using Elecsys PIGF and sFlt1 immunoassays (Schiettecatte et al. 2010). As circulating PlGF might be increased in patients with ischemic cardiomyopathy (Nakamura et al. 2009), parallel proBNP determinations served as a surrogate marker of myocardial function. Patients with elevated proBNP $(>500 \mathrm{pg} / \mathrm{ml})$ were not excluded from the analysis. However, the outcome of the analyses of grading, survival, and TTP in the overall cohorts and subgroups remained unchanged, if these patients were excluded. PIGF levels from cell culture supernatants were measured using Quantikine ELISA kits (R\&D Systems) according to the manufacturer.

\section{Immunohistochemical analyses}

Cryostat-sections were fixed in $4 \%$ paraformaldehyde (PFA). Immunoperoxidase-staining was performed using Vectastain Elite ABC-kit (Vector Laboratories, WertheimBettingen, Germany) and AEC as substrate chromogen (DAKO, Hamburg, Germany). The antibody to PlGF was diluted 1:100, and was omitted in negative controls. For a semi-quantitative evaluation of immunoreactivity, the immunoreactive area was determined relative to the total field measured using AxioVision (Zeiss, Jena, Germany).

\section{Growth assays}

In 24-well dishes, $10^{5}$ cells/well were plated and allowed to attach for $6 \mathrm{~h}$. Following stimulation with PlGF for $48 \mathrm{~h}$, cell numbers were counted using a Neubauer hemocytometer.

\section{Migration assays}

A number of $2 \times 10^{5}$ cells/insert were placed in serum-free medium in the upper well of a chemotaxis chamber and allowed to migrate for $20 \mathrm{~h}$ toward PIGF added to the bottom well. Migrated cells were stained and quantified by counting 12 standardized fields at $200 \times$ magnification (refer to Supplementary Methods, see section on supplementary data given at the end of this article for details).

\section{BON NET orthotopic tumor model}

Female NMRI ${ }^{\mathrm{nu} / \mathrm{nu}}$ mice (21-25 g) were from Taconics (Bomholt, Denmark). Animal care followed institutional guidelines and experiments were approved by local animal research authorities. Mice were anesthetized by i.p. administration of Ketanest $(100 \mathrm{mg} / \mathrm{kg})$ and Rompun $(10 \mathrm{mg} / \mathrm{kg})$. For tumor induction, the pancreas was exposed and $1 \times 10^{6}$ BON cells were injected into the head of the pancreas as previously described (Detjen et al. 2010). Treatment of engrafted tumors was initiated at week 3 following tumor cell implantation. Antibodies to PlGF and isotype-matched $\operatorname{IgG}_{1}$ control antibodies were administered by i.p. injection ( $25 \mathrm{mg} / \mathrm{kg}$; twice weekly).

Published by Bioscientifica Ltd. 
Mice were sacrificed after 9 weeks, and primary tumors were removed and weighted.

\section{Statistical analysis}

Data are presented as mean \pm s.E.M., circulating levels of PlGF and sFlt1 as median with interquartile ranges. Statistical significance was determined by $t$-test, Fisher's exact test, and Mann-Whitney $U$ test using SPSS (v18.0) and GraphPad Prism (v5.0; San-Diego, CA, USA). Tumorrelated survival and TTP were calculated based on the date of blood sampling and analyzed using the Kaplan-Meier method and Log-rank test. Cox proportional hazards regression model was used for multivariate analysis. ${ }^{*} P<0.05$ values were considered significant; all tests were two-sided.

\section{Results}

PIGF serum levels are elevated in patients with pNETs

Given that PlGF is released into systemic circulation, we initially determined circulating PlGF in sera of patients with pNETs and healthy controls (Table 1). Median circulating PIGF concentration was found elevated to $19.5 \mathrm{pg} / \mathrm{ml}$ in pNET patients compared with $12.3 \mathrm{pg} / \mathrm{ml}$ in healthy controls (Fig. 1A). Receiver operating characteristic (ROC) analysis displayed $79.5 \%$ sensitivity and $82.8 \%$ specificity for the discrimination between patients with pNETs and controls at a cut-off level of $15.35 \mathrm{pg} / \mathrm{ml}$ (Fig. 1B), indicating that pNETs are associated with an increase in circulating PIGF.

As binding of PlGF to its soluble receptor Flt1 (sFlt1) may diminish its biological activity, we also determined sFlt1 levels. Though we found circulating sFlt1 increased in pNET patients compared with controls (Fig. 1C and D), the ratio PlGF:sFlt1 remained significantly elevated in patients with pNETs (Fig. 1E and F).

\section{Elevated PIGF serum levels correlate with tumor grading of pNETs}

We next hypothesized that circulating PIGF levels in patients with pNETs reflect histopathological properties and/or the clinical course of the disease. No correlation of PlGF with TNM classification was obtained. In particular, circulating PlGF did not discriminate between localized vs metastatic disease (Fig. 2A). However median PlGF levels progressively increased from grade 1 (G1) to 3 (G3) tumors (Fig. 2C).

\section{Levels of circulating sFlt1 correlate with metastatic disease in pNETs}

As sFlt1 has been proposed as a surrogate marker of tumor progression, we tested the association of sFlt 1 levels with clinical parameters. Different from PlGF, sFlt1 levels correlated with metastatic disease (Fig. 2B). Median sFlt1 levels also progressively increased with grading (Fig. 2D).

\section{Elevated PIGF serum levels predict reduced tumor-related survival in pNETs}

The association of circulating PlGF and sFlt1 with tumor grade raised the question, whether these serum parameters reflected the prognosis. Accordingly, patients were grouped by high ( $>50$ th percentile) or low $(\leq 50$ th percentile) levels of circulating PIGF, respectively, and Kaplan-Meier curves based on tumor-related survival were generated. Circulating PlGF levels $>$ 50th percentile were associated with poor prognosis and predicted shorter tumor-related survival with a median survival of 4.52 years, whereas median survival in patients with low-PlGF serum concentrations had not yet been reached (hazard ratio: 2.35; 95\% CI: 1.08-5.10; Log-rank $P=0.031$; Fig. 2E). Subsequent multivariate analysis confirmed tumor grade, but not circulating PlGF as an independent prognostic parameter in the overall cohort (not shown), which is in accordance with the correlation of PlGF levels and grading described above. In contrast to PlGF, neither sFlt1 nor the PlGF:sFlt1 ratio correlated with tumor-related survival (Fig. 2F, and not shown).

\section{Prospective evaluation of PIGF as prognostic biomarker in NETs}

As our retrospective analysis suggested circulating PIGF as prognostic biomarker, we next sought to determine PlGF and sFlt1 in an independent validation cohort. Clinically, the availability of a prognostic biomarker would benefit the management of patients with lower grade tumors (G1 and G2), which often require a personalized therapeutic strategy to accompany them for decades. In order to be able to focus on lower grade tumors, yet recruit a prospective cohort within a reasonable time frame, we opened our analyses to intestinal NETs. Accordingly, patients with either low-grade pNETs or intestinal NETs were enrolled in a prospective study (Table 1). PlGF levels were found elevated in the overall cohort $(n=87)$, as well as in the pNET and intestinal subgroups (Fig. 3A), confirming our initial observation. We furthermore

Published by Bioscientifica Ltd. 

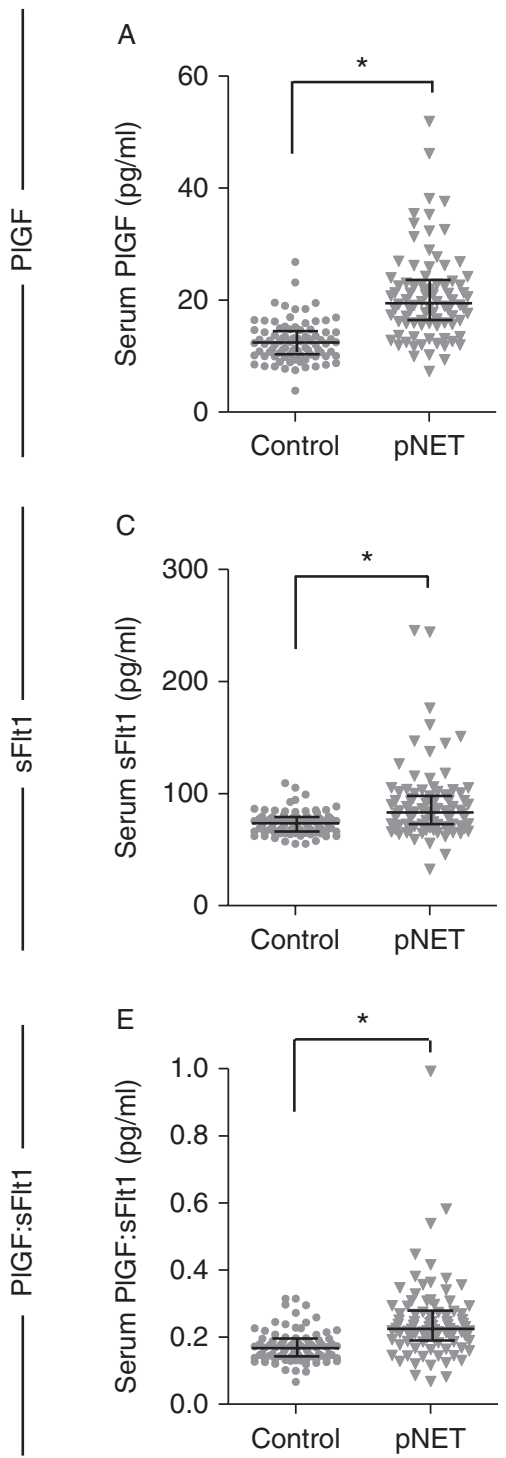

Figure 1

Elevated circulating PIGF and sFlt1 levels in patients with pNETs. (A) PIGF serum concentrations in healthy controls $(n=87)$ and patients with pNET $(n=88)$. Shown is the scatter dot plot with the median and interquartile range, $* P<0.0001$, Mann-Whitney $U$ test. (B) Panel depicts corresponding ROC curve of circulating PIGF. AUC $=0.85,95 \% \mathrm{Cl}: 0.80-0.91, * P<0.0001$. (C) sFlt1 serum concentrations in healthy controls $(n=87)$ and patients with pNET $(n=88)$. Shown is the scatter dot plot with a median of $73.9 \mathrm{pg} / \mathrm{ml}$ in healthy controls vs $83.6 \mathrm{pg} / \mathrm{ml}$ in pNET patients and interquartile range,

confirmed increased sFlt1 concentrations as well as an elevated PlGF:sFlt1 ratio in NETs compared with healthy controls (Supplementary Figure 1, see section on supplementary data given at the end of this article).

Due to their slow progression, we were unable to determine tumor-related survival in the subgroup of intestinal NETs, and hence had to restrict survival analyses to pNET patients. Different from the retrospective analysis,
B

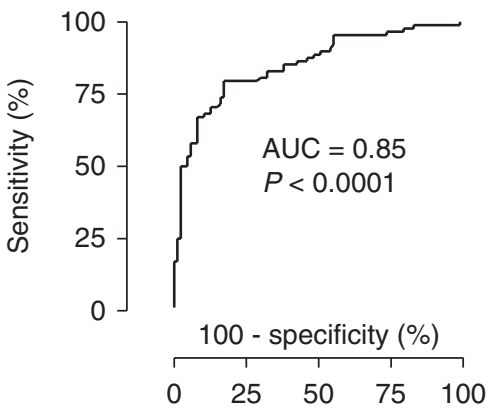

D

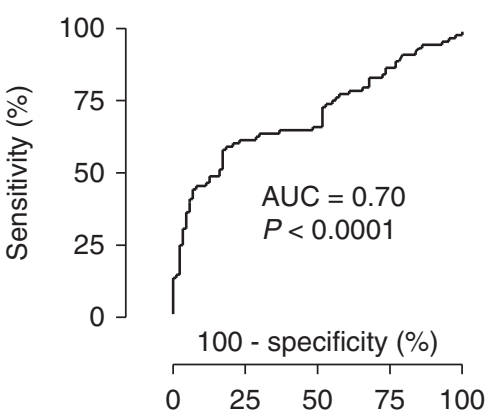

$\mathrm{F}$

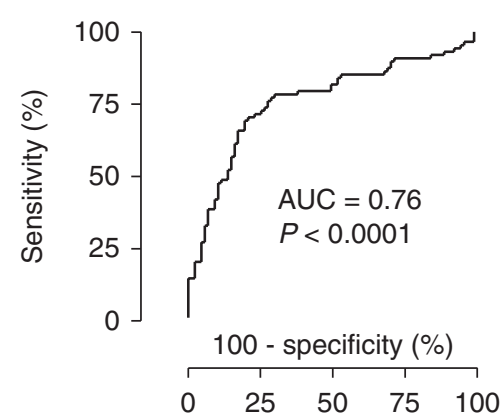

${ }^{\star} P<0.0001$, Mann-Whitney $U$ test. (D) Panel depicts corresponding ROC curve of circulating sFlt1. AUC $=0.70,95 \% \mathrm{Cl}: 0.62-0.78, P<0.0001$. (E) PIGF:sFlt1 ratios in healthy controls $(n=87)$ and patients with pNET $(n=88)$. Shown is the scatter dot plot with the median of 0.17 in healthy controls vs 0.23 in pNET patients and interquartile range, ${ }^{\star} P<0.0001$, Mann-Whitney $U$ test. (F) Panel depicts corresponding ROC curve of PIGF:sFlt1 ratio. AUC $=0.76,95 \% \mathrm{Cl}: 0.69-0.84,{ }^{\star} P<0.0001$.

a distinct cut-off value rather than the cohort-dependent median was required. As PlGF values from low-grade pNETs revealed considerable overlap with healthy controls, we choose the cut-off that best separated NET patients from healthy controls in our ROC analyses ( $15.35 \mathrm{pg} / \mathrm{ml}$; Fig. 1B). Kaplan-Meier analyses using this cut-off indicated favorable tumor-related survival for individuals with non-pathologic circulating PlGF when 

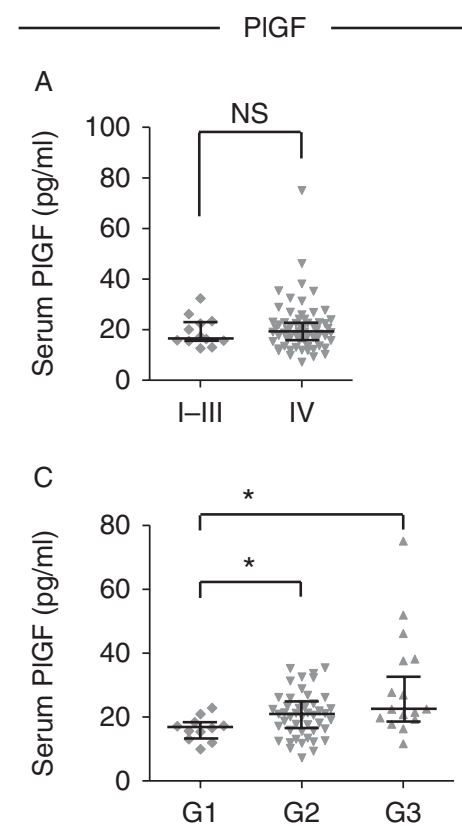

E

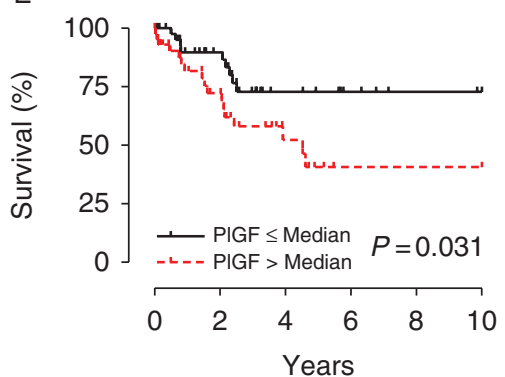

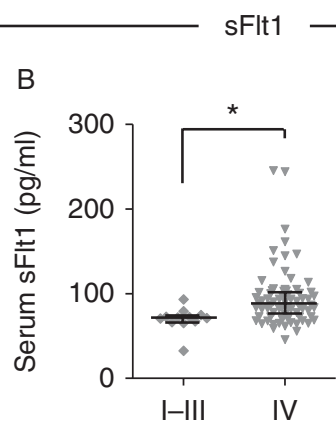
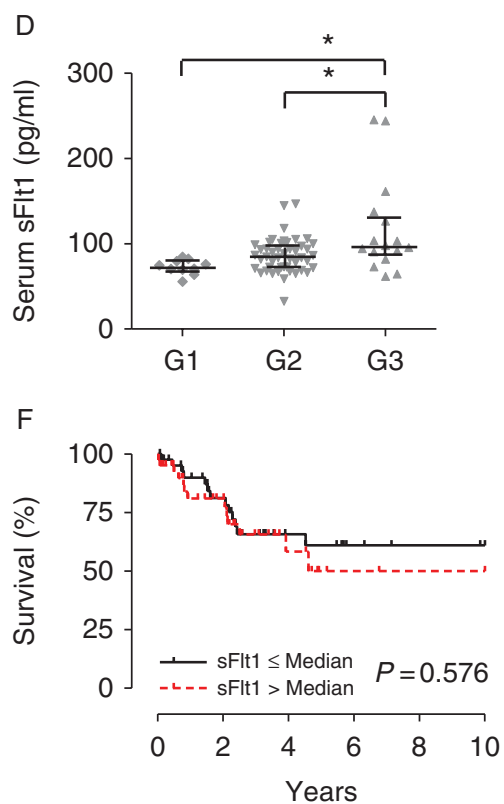

* $P=0.002$ for $\mathrm{G} 1$ vs G3, Mann-Whitney $U$ test. (D) Correlation between serum sFlt1 levels and histological tumor grading (groups as in C). Median sFlt1 was $74.8 \mathrm{pg} / \mathrm{ml}$ for $\mathrm{G} 1,84.6 \mathrm{pg} / \mathrm{ml}$ for $\mathrm{G} 2$, and $96.7 \mathrm{pg} / \mathrm{ml}$ for $\mathrm{G} 3$, respectively. Shown is the scatter dot plot with the median and interquartile range; ${ }^{*}=0.013$ for $\mathrm{G} 1$ vs G3, ${ }^{*} P=0.032$ for $\mathrm{G} 2$ vs G3, Mann-Whitney $U$ test. (E) Kaplan-Meier survival curve of pNET patients with high vs low levels of circulating PIGF. Patients were allocated to a group with high ( $>50$ th percentile, corresponds to $>19.3 \mathrm{pg} / \mathrm{ml}, n=43$ ) or low ( $\leq 50$ th percentile, $n=44)$ PIGF serum levels, and Kaplan-Meier analyses were conducted; hazard ratio: $2.35 ; 95 \% \mathrm{Cl}$ : 1.08-5.10; Log-rank $P=0.031$. (F) Kaplan-Meier analysis of tumor-related survival of pNET patients with high vs low levels of circulating sFlt1. Patients were allocated to a group with high ( $>50$ th percentile, corresponds to $>83.6 \mathrm{pg} / \mathrm{ml}, n=43$ ) or low ( $\leq 50$ th percentile, $n=44)$ sFlt1 serum levels, and Kaplan-Meier analyses were conducted; hazard ratio: $1.25 ; 95 \% \mathrm{Cl}: 0.57-2.71$; Log-rank $P=0.576$.

therefore we evaluated TTP instead. TTP could be determined in 47 out of 57 patients with G1 and G2 intestinal NETs, which were enrolled with stable disease. Kaplan-Meier analysis separating patients based on normal vs pathologic PlGF levels did not reveal significant differences. However, TTP was significantly reduced in patients with circulating PlGF above median (hazard ratio:

Published by Bioscientifica Ltd. http://erc.endocrinology-journals.org DOI: $10.1530 / E R C-12-0223$
(C) 2013 Society for Endocrinology Printed in Great Britain 


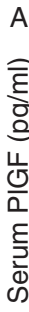

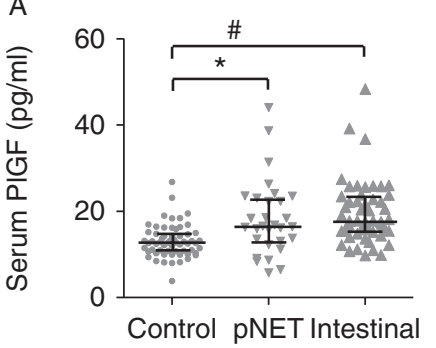

NET

B
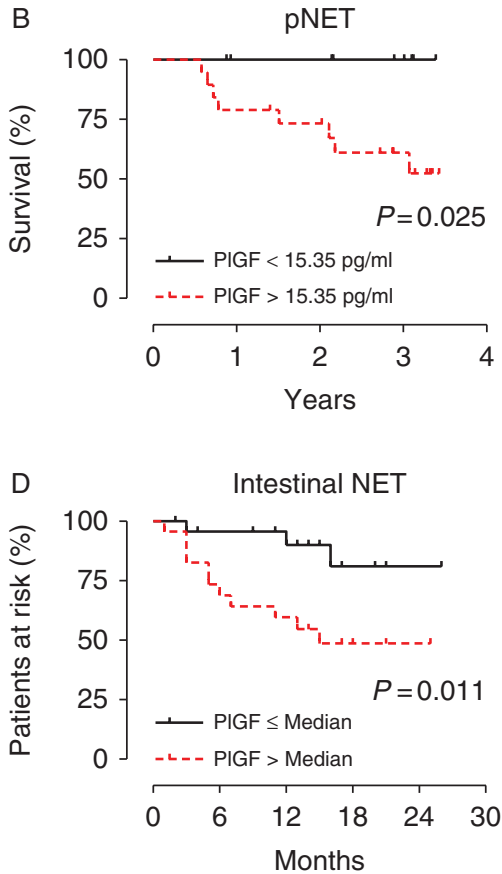

Figure 3

Prospective confirmation of elevated circulating PIGF levels and its prognostic relevance in patients with pancreatic and intestinal NETs. (A) PIGF serum concentrations in healthy controls $(n=87)$ and a prospective cohort of patients with pNET $(n=30)$ and intestinal NETs $(n=57)$. Shown is the scatter dot plot with a median of $12.3 \mathrm{pg} / \mathrm{ml}$ in healthy controls vs $16.5 \mathrm{pg} / \mathrm{ml}$ in $\mathrm{pNETs}$ and $17.6 \mathrm{pg} / \mathrm{ml}$ in intestinal NETs, and the respective interquartile range, ${ }^{*} P=0.001$ and ${ }^{\#} P<0.0001$, Mann-Whitney $U$ test. (B) Pathologic PIGF levels were associated with reduced tumor-related survival in low-grade pNETs of the prospective cohort. Patients were allocated to a group with pathological ( $>15.35 \mathrm{pg} / \mathrm{ml}, n=52$ ) or normal $(<15.35 \mathrm{pg} / \mathrm{ml}, n=18)$ serum PIGF levels, and Kaplan-Meier analyses were performed to compare tumor-related survival; Log-rank $P=0.025$.

(C) Similar results were obtained with the subgroup of G2 pNETs when using

4.01; 95\% CI: 1.38-11.65; Log-rank $P=0.011$; Fig. 3D). Conversely, patients experiencing disease progression within 6 months presented higher median baseline PlGF levels than patients with stable disease throughout this period ( 26.7 vs $16.6 \mathrm{pg} / \mathrm{ml} ; P=0.009)$. Moreover, median PlGF levels further stratified the clinically heterogeneous group of G2 intestinal NETs into prognostic subgroups
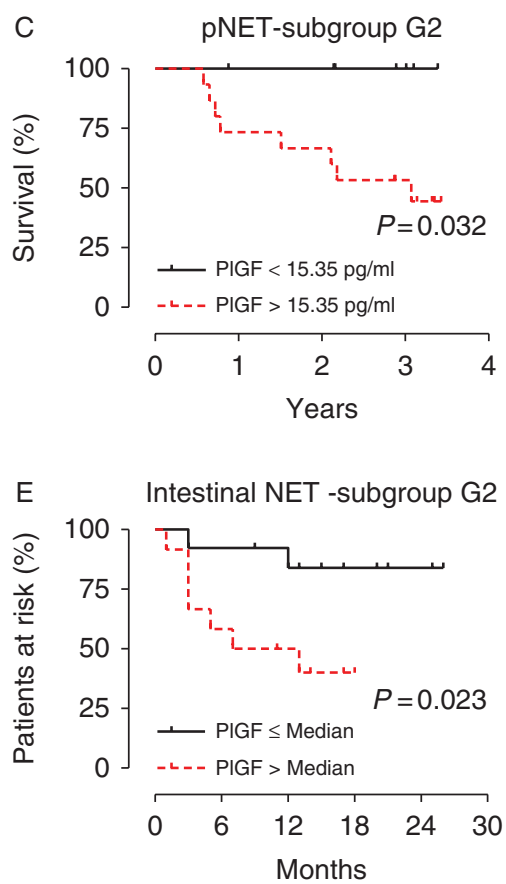

the cut-off value of $15.35 \mathrm{pg} / \mathrm{ml}$; Log-rank $P=0.032$. (D) Circulating PIGF values above median identify patients with rapid disease progression in intestinal NETs. Shown is a Kaplan-Meier analysis of time-to-progression in patients with intestinal NETs allocated to a group with high ( $>50$ th percentile, corresponds to $>17.1 \mathrm{pg} / \mathrm{ml}, n=23$ ) or low ( $\leq 50$ th percentile, $n=24$ ) PIGF serum levels; TTP 15 months vs undefined; hazard ratio: 4.01; 95\% Cl: 1.38-11.65; Log-rank $P=0.011$. (E) Elevated circulating PIGF levels discriminate prognostic subgroups within the group of patients with grade 2 intestinal NETs. Patients were allocated to a group with high ( $>50$ th percentile, corresponds to $>17.8 \mathrm{pg} / \mathrm{ml}, n=12$ ) or low ( $\leq 50$ th percentile, $n=13$ ) serum PIGF levels, and Kaplan-Meier analyses were performed to compare time-to-progression; TTP 10 months vs undefined; hazard ratio: 4.95; 95\% Cl: $1.25-19.60$; Log-rank $P=0.023$.

(hazard ratio: 4.95; 95\% CI: 1.25-19.60; Log-rank $P=0.023$; Fig. 3E). Finally, PlGF, but not grading or biotherapy with SSAs (29 out of 47 patients), constituted an independent prognostic parameter in the multivariate analysis of the intestinal NET cohort (Table 2). As grading is expected to emerge as an independent prognostic parameter in intestinal NETs, we inspected Ki67 values

Published by Bioscientifica Ltd. 
Table 2 Multivariate analysis for time-to-progression (TTP) in intestinal NETs $(n=47)$.

\begin{tabular}{|c|c|c|}
\hline Covariate & $P$ value & HR $(95 \% \mathrm{Cl})$ \\
\hline Age (years) & 0.601 & $0.99(0.93-1.04)$ \\
\hline Sex (female/male) & 0.450 & $0.64(0.20-2.02)$ \\
\hline TNM-stage & 0.988 & $0.00^{\mathrm{a}}$ \\
\hline Grading & 0.737 & $1.21(0.40-3.71)$ \\
\hline Biotherapy (SSA) & 0.349 & $1.76(0.54-5.78)$ \\
\hline $\begin{array}{l}\text { Serum PIGF levels } \\
\text { ( }>\text { median to } \\
\leq \text { median) }\end{array}$ & 0.029 & $4.87(1.18-20.13)$ \\
\hline
\end{tabular}

HR, hazard ratio; SSA, somatostatin analogs.

${ }^{a}$ Out of 47 subjects 46 were TNM-stage IV.

in our cohort in more detail. Indeed, 16 of the 21 G2 intestinal NETs had Ki67 values that were lower or equal to $5 \%$, four had Ki67 values between 5 and 10\%, and only one tumor had more than 10\% Ki67 positive cells. We therefore speculate that this low-proliferative activity accounted for the comparable TTP in G1 and G2 subgroups.

Taken together, our prospective approach confirmed elevated circulating PlGF levels in pNETs and intestinal NETs and suggested PlGF levels as a prognostic parameter.

\section{pNETs are associated with de novo expression of PIGF}

As PIGF may be expressed and bound by cells from various tumor compartments, we aimed to further specify the abundance and location of PlGF in pNETs. Based on histomorphological criteria, pNET samples $(n=23)$ consistently displayed strong PlGF expression in stromal cells, such as endothelial and inflammatory cells (Fig. 4A, $\mathrm{B}, \mathrm{C}$ and $\mathrm{E}$ ), and occasionally weak immunoreactivity for PlGF in the tumor cell compartment. In contrast, no staining was observed in non-transformed endocrine or exocrine pancreatic tissues, including their stroma (Fig. 4D and $\mathrm{E}$ ), indicating de novo expression of PlGF in pNETs.

\section{PIGF enhances proliferation and motility of NET cells and is induced by targeted therapies in vitro}

To functionally address the role of PlGF, we initially determined effects of PIGF stimulation on NET cell biology in vitro. A panel of pancreatic (BON and QGP-1), ileal (KRJ-I), and bronchial (H727) NET cell lines was used. PlGF determination from supernatants of these tumor cell cultures was at (BON) or below (QGP-1, H727) the detection limit (not shown), and thus in agreement with the sparse immunohistochemical reactivity of epithelial tumor cells. However, expression analysis readily revealed the presence of at least one of the known PlGF receptors, Flt1, NRP1, and NRP2 in these NET cell lines (Supplementary Figure 2, see section on supplementary data given at the end of this article), thereby enabling responsiveness to paracrine PlGF stimulation. Indeed, recombinant PlGF enhanced proliferation of all four NET cell lines tested
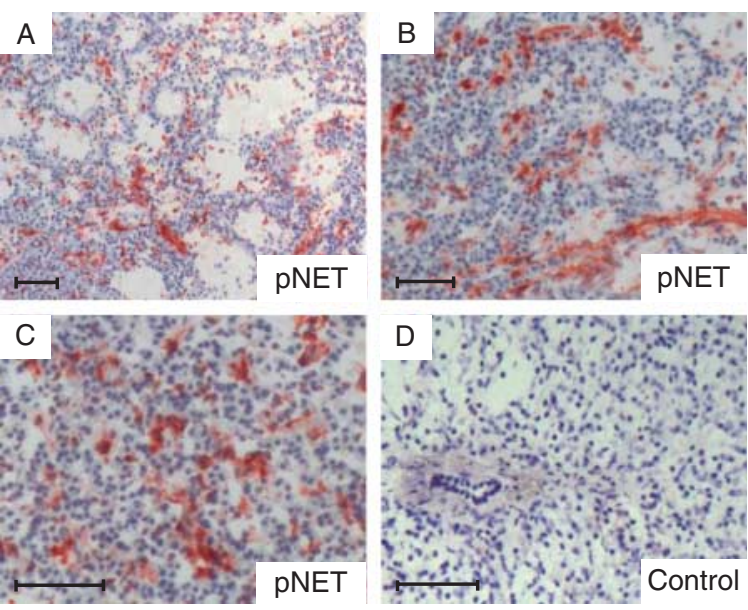

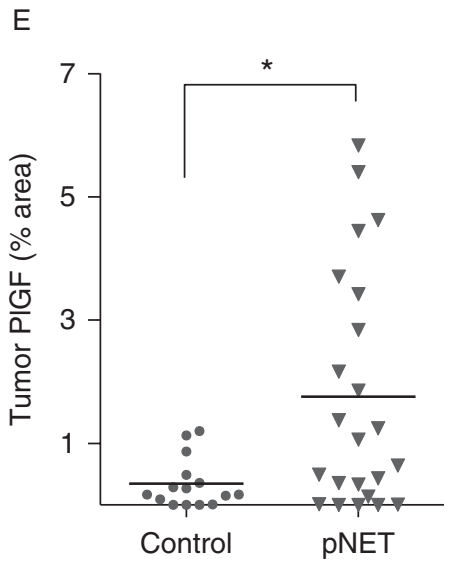

\section{Figure 4}

De novo expression of PIGF occurs in human pNETs. (A, B, C and D) Representative immunohistochemistry for PIGF on cryosections of clinical specimens from patients with pNETs (A, B and C) and respective adjacent non-transformed tissue (D). Scale bars $=100 \mu \mathrm{m}$. (E) Semiquantitative analysis of overall PIGF expression in tumor epithelial and stromal cells of clinical specimens $(n=23)$. Immunoreactivity for PIGF was determined from the percentage of immunoreactive area/total tumor area, without additional assessment of staining intensity. Data represent mean \pm s.E.M. ${ }^{\star} P<0.05 ;$-test.

Published by Bioscientifica Ltd. 
(Fig. 5A, B and C; H727 not shown). In addition to this mitogenic action, PlGF substantially enhanced directed migration of BON and QGP-1 cells (Fig. 5D, E, F and G). Taken together, exogenous PIGF stimulation elicited biological responses that were consistent with a more aggressive tumor phenotype.

In view of the biological action of PlGF on NET cells, we next tested, whether recently approved targeted therapies affect PlGF production of NET cells in vitro. In order to allow for paracrine tumor cell/stroma interactions, we determined PlGF production from different endothelial cell and fibroblast preparations, including NET-derived tumor fibroblasts. PIGF was consistently detected in supernatants from endothelial cells, but not from fibroblast cultures (not shown), prompting us to choose mixed spheroid cultures of BON cells with endothelial cells as an in vitro approach (see Supplementary Methods). Incubation of spheroid co-cultures with the tyrosine-kinase inhibitor sunitinib, but not with the mTOR-inhibitor everolimus over $72 \mathrm{~h}$ elevated PlGF levels in the supernatant $(264.3 \pm 38.7 \%$ of control; $P=0.02$; and $122.3 \pm 10.5 \%$ of control; $P=0.13$ ). Thus, PlGF release increased in response to sunitinib, suggesting that PlGF induction in NETs may occur following antiangiogenic treatment.

\section{Blocking PIGF inhibits growth of orthotopic NETs}

Finally, we decided to investigate the function of PlGF in vivo, using an established preclinical NET model. Accordingly, BON orthotopic pNET xenografts were grown in NMRI ${ }^{\mathrm{nu} / \mathrm{nu}}$ mice and engrafted tumors treated with either isotype-matched control $\operatorname{IgG}_{1}$ or a combination of neutralizing antibodies to mouse and human PlGF from week 3 following tumor cell implantation. By the end of the experiment in week 9, functional inactivation of tumor cell and stroma-derived PlGF by the neutralizing antibodies had resulted in a significant reduction of tumor weight, indicating that PlGF supports NET growth in vivo and constitutes a therapeutic target (Fig. 5H, I and J).

\section{Discussion}

The current study highlights PIGF as a novel, stromaderived growth factor in pancreatic and intestinal NETs. In vitro, PlGF enhanced proliferation and migration of NET cell lines, suggesting that PIGF directly affects NET cell biology. In vivo, blocking PlGF using neutralizing antibodies reduced growth of orthotopic BON NET xenograft tumors, indicating that PlGF represents a therapeutic target in preclinical NET models. In the clinical situation, elevated circulating PIGF levels were associated with reduced tumor-related survival and/or shorter TTP in NETs, suggesting circulating PIGF as an easily accessible candidate prognostic biomarker.

The therapeutic concept of antiangiogenesis has created much interest in tumor-type specific angioregulatory growth factors. Studies conducted in NETs found that VEGF-A, the prototype angiogenic factor in cancer, is highly expressed in intestinal NETs (Terris et al. 1998) but was found less abundant in pNETs, inversely correlated to microvascular density, and did not convey prognostic information in pNETs (Terris et al. 1998, Marion-Audibert et al. 2003, Couvelard et al. 2005). Here, we find that PlGF, a member of the VEGF family, is prominently induced in the stroma of pNETs. Although de novo expression of PIGF reportedly may occur in the tumor cell compartment (Fischer et al. 2008), our analysis suggests that this was rarely the case in pNETs. Rather, the tumor stroma of pNETs uniformly revealed abundant PIGF immunoreactivity. Genetic and pharmacological evidence attests to the functional relevance of stroma-derived PlGF in that inactivation of stromal PlGF impaired (Carmeliet et al. 2001, Schmidt et al. 2011), whereas transgene overexpression of stromal PlGF stimulated tumor growth, angiogenesis, and metastasis in mouse models (Marcellini et al. 2006, Fischer et al. 2007, 2008). Given that the known PlGF receptors, Flt1, and neuropilins were shown expressed in NETs (Terris et al. 1998, von Marschall et al. 2003), our current observation of stromal PlGF expression suggests the presence of auto-/paracrine signaling loops. Functionally, PIGF stimulated proliferation and migration of NET cells in vitro, which is in line with published results revealing stimulatory actions of PlGF on proliferation of pancreatic tumor cells (Fischer et al. 2007), as well as on migration of glioma, breast, and lung cancer cells (Fischer et al. 2008, Taylor et al. 2010). More importantly, we were able to reduce the growth of BON NET xenograft tumors using neutralizing antibodies to functionally inactivate tumor cell- and stroma-derived PIGF.

A second line of evidence strongly implicates PIGF in the pathology of NETs: circulating PIGF levels were elevated in pNET patients, correlated with tumor grade, and predicted poor clinical outcome. In contrast, PlGF did not correlate with TNM stages and did not differ between localized (TNM stages I-III) and metastatic disease (TNM stage IV). We therefore favor the concept that high circulating PlGF levels reflected a more aggressive tumor biology rather than a more extensive tumor load.

Published by Bioscientifica Ltd. 

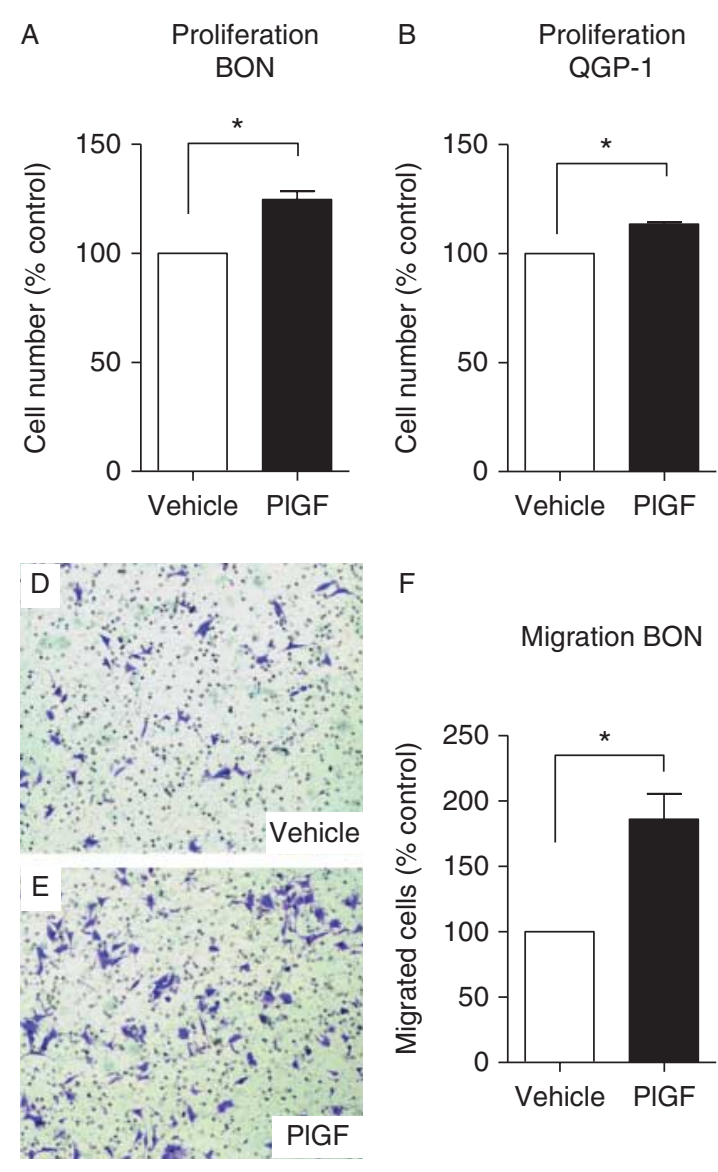

$F$
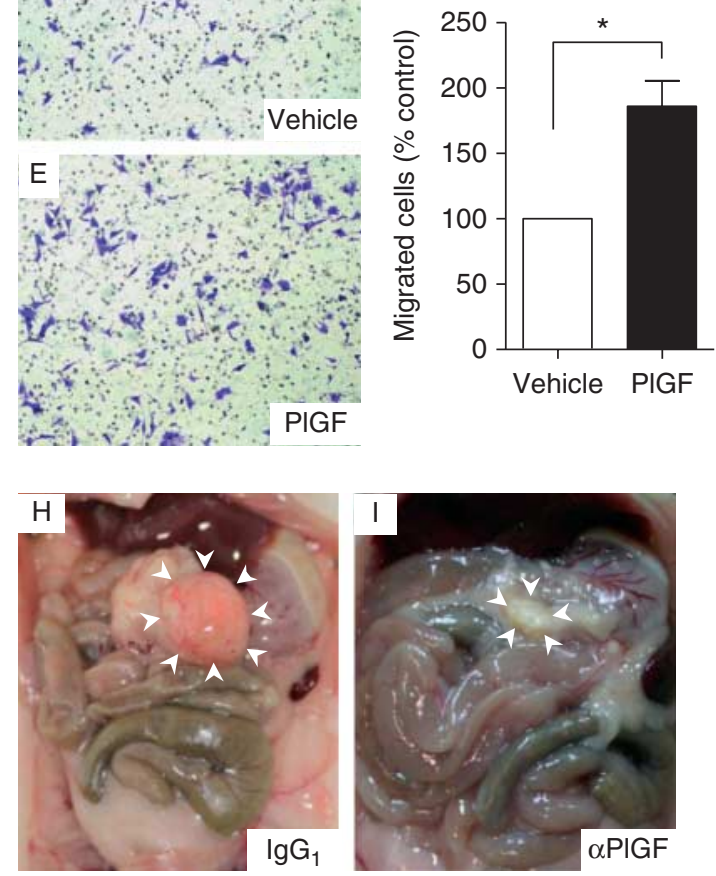
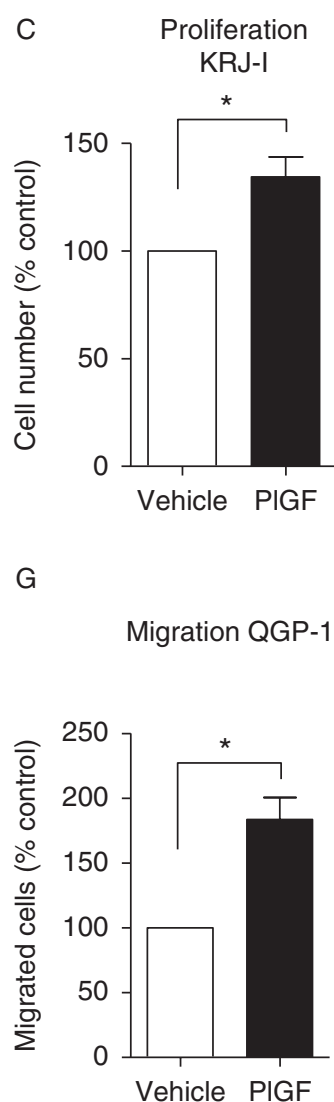

G

Migration QGP-1

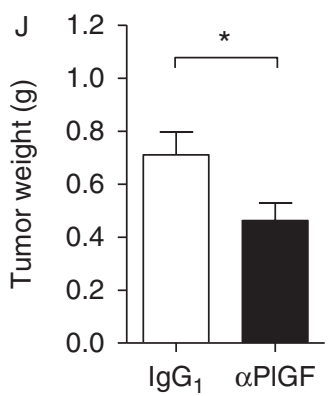

\section{Figure 5}

PIGF enhances proliferation and directed migration of neuroendocrine tumor cells in vitro, and conversely, blocking PIGF inhibits growth of orthotopic NETs in vivo. (A) PIGF $(100 \mathrm{ng} / \mathrm{ml})$ stimulates growth of BON cells to $124.7 \pm 3.8 \%$ of vehicle control over $48 \mathrm{~h}$. (B and C) Similarly, PIGF increased cell numbers of QGP-1 (B) and KRJ-I (C) cultures to $113.5 \pm 0.8$, and $134.5 \pm 9.2 \%$ of controls respectively. All experiments were at least conducted three times, each in duplicates. Data represent means \pm s.E.M. $* P<0.05$; $t$-test. (D, E, F and G) PIGF $(100 \mathrm{ng} / \mathrm{ml})$ functions as chemoattractant and stimulates the directed migration of $B O N(D, E$ and $F)$ and QGP-1 (G) NET cells in transwell assays to $186.0 \pm 19.4$ and $183.7 \pm 17.0 \%$ of

Although expression of PlGF in tumor tissues was proposed as prognostic marker for progression and survival in gastric, colorectal, NSCLC, hepatocellular, and breast cancer (Parr et al. 2005, Wei et al. 2005, Fischer et al. 2008), vehicle controls respectively. Representative fields from membranes show migrated cells after staining with crystal violet ( $D$ and $E$ ). All experiments were at least conducted three times, each in duplicates. Data represent means \pm s.E.M. ${ }^{*} P<0.05$; $t$-test. $(H, I$ and J) Effects of anti-PIGF antibodies on growth of BON NET tumors. NMRI ${ }^{\text {nu/nu }}$ mice with engrafted orthotopic pancreatic NET tumors were treated with either isotype-matched control $\mathrm{IgG}_{1}$ antibodies ( $n=13$; illustrated in $\mathrm{H}$ ) or a combination of neutralizing antibodies to mouse and human PIGF ( $n=16$; illustrated in I). Bar graph represents tumor weight at the end of the experiment as means \pm s.E.M. (J; $P=0.031)$.

relatively few studies evaluated circulating levels of PIGF. Results linked high circulating PIGF to adverse prognosis in renal (Matsumoto et al. 2003) and oral squamous cell carcinoma (Cheng et al. 2012) but not in hepatocellular 
cancer (Nagaoka et al. 2010), and high preoperative PlGF levels predicted reduced recurrence-free and overall survival in colorectal cancer patients undergoing curative surgery (Wei et al. 2009, Rahbari et al. 2011). The latter data fit with our observation that PlGF levels $>50$ th percentile correlated with shorter TTP in the prospective intestinal NET cohort. Indeed, we identified circulating PlGF as a prognostic indicator of TTP in an intestinal NET collective with low overall proliferative activity, in which grading was unable to separate prognostic subgroups. Furthermore, pathologic PlGF levels identified distinct subgroups regarding tumor-related survival within the heterogeneous group of G2 pNETs in our prospective approach. Currently, we cannot pinpoint the cause of the more robust separation of prognostic subgroups of G2 intestinal NETs by median PIGF levels compared with the separation of G2 pNET prognostic subgroups by pathologic PlGF levels. Difference in end points (tumor-related survival vs TTP), differences in NET types (pNET vs intestinal NET), or differences in treatment modalities offer potential explanations that will have to be thoroughly evaluated in future prospective studies.

Irrespective of such adjustments, our current data established the link from circulating PlGF to disease prognosis, which could have considerable translational impact on the management of NETs based on three considerations:

First, advanced G2 tumors comprise a large and clinically heterogeneous group of patients, in which the course of disease and resultant treatment decisions are variable, with choices currently based on empirical knowledge rather than objective parameters. In the current study, high PlGF levels in patients with G2 tumors specifically characterized individuals with an unfavorable prognosis. Notably, absolute Ki67 values within the G2 subgroup did not correlate to PlGF levels ( $r=0.156 ; P=0.215)$, suggesting that PlGF conveyed prognostic information that is distinct from Ki67-based grading. Hence, circulating PIGF may serve to further stratify patients with G2 tumors and help to optimize clinical management, as it could identify patients that benefit from immediate/more aggressive treatment and/or shorter monitoring intervals.

Second, our preclinical results in the orthotopic NET xenograft model characterize PlGF as a therapeutic target in NETs. Compelling preclinical evidence established blocking PlGF using anti-PlGF antibodies as effective strategy to inhibit tumor growth and metastasis (Fischer et al. 2007, Coenegrachts et al. 2010, Van de Veire et al. 2010, Schmidt et al. 2011, Yao et al. 2011a, Heindryckx et al. 2012). As PlGF is a disease-specific factor and redundant for physiological vessel growth (Carmeliet et al. 2001, Fischer et al. 2007), inhibition of PlGF is likely to exhibit less side effects than VEGF-A/VEGFR2-based therapies (Fischer et al. 2007, Verheul \& Pinedo 2007). In NET disease, which often requires long-term treatment regimens, prevention of co-morbidity, which might be of greater risk to patients than the malignancy itself, is of crucial importance. So far, a phase I clinical trial with the humanized anti-PlGF antibody TB-403 has proven lack of toxicity (Martinsson-Niskanen et al. 2011, Lassen et al. 2012). Moreover the recent approval of sunitinib for the treatment of pNETs (Raymond et al. 2011) might have substantial implications on considering PlGF as therapeutic target in these tumors, as sunitinib efficiently blocks Flt1 signaling (Fischer et al. 2008).

Third, changes in circulating PlGF may occur as a consequence of treatment. Patients with NETs may undergo decades of therapy. Apart from side effects of long-term treatments, resistance development therefore constitutes a major concern, especially when considering antiangiogenic treatments (Paez-Ribes et al. 2009). In this context, mouse models revealed that circulating and tumoral PlGF levels increase upon VEGF inhibition and conventional chemotherapies, resulting in recruitment of proangiogenic macrophages and angiogenic escape (Fischer et al. 2007). Similarly, chronic exposure of colorectal cancer cells in vitro to bevacizumab increased the expression of PlGF and consequently enhanced tumor cell migration and invasion, and metastatic potential in vivo (Fan et al. 2011). Of clinical relevance, induction of circulating PlGF occurred in patients receiving VEGF inhibitors for treatment of colorectal and renal cell cancers and glioblastoma (Motzer et al. 2006, Batchelor et al. 2007, Fischer et al. 2007, Willett et al. 2009, de Groot et al. 2011). Thus, it is tempting to speculate that early and/or transient increases in circulating PIGF may predict therapy response, while long-term induction of circulating PlGF might constitute a functional mechanism and/or indicator of resistance development. Given the recent approvals of sunitinib and everolimus for treatment of pNETs, circulating PIGF may represent an easily accessible candidate biomarker for monitoring therapy response and/or disease progression. While sunitinib-dependent effects on circulating PlGF levels have not yet been determined in NET patients, PIGF measurements from the RADIANT-3 trial reported a transient reduction in response to everolimus, which is difficult to interpret. At a first glance, the decrease of circulating PlGF levels seems counterintuitive in view of the antiangiogenic activity attributed to everolimus, which might be expected to induce a compensatory rise of PlGF. However, reported

Published by Bioscientifica Ltd. 
values give a snapshot of circulating PlGF levels obtained at 28 days of treatment, and the moderate antiangiogenic action of everolimus may require a longer treatment period for efficient induction of an angiogenic escape. Furthermore, PlGF reduction may have resulted from reduced tumor burden in treatment responders.

With the advent of novel therapies for NETs, a personalized therapy may have come into reach, but a definition of biomarker profiles that are useful for the stratification of subgroups is mandatory. PlGF holds promise for NETs in multiple ways: as a prognostic marker, as potential therapeutic target, and - possibly - as a response marker for selected systemic therapies. Our current analyses provide an intriguing link from high PlGF serum levels to poor outcome that deserves an urgent prospective follow up in larger cohorts of pancreatic and intestinal NETs.

Thus, our data provide a compelling basis for a more extensive prospective evaluation of PlGF in larger and more diverse NET cohorts. Finally, our observations strongly advocate an inclusion of PlGF into the portfolio of biomarkers in ongoing and/or further prospective NET trials.

\section{Supplementary data}

This is linked to the online version of the paper at http://dx.doi.org/10.1530/ ERC-12-0223.

\section{Declaration of interest}

G Hess was previously an employee of Roche Diagnostics and is currently a consultant to Roche Diagnostics. JM Stassen was previously an employee of ThromboGenics NV and is currently a scientific advisor to ThromboGenics NV. The other authors declare that there is no conflict of interest that could be perceived as prejudicing the impartiality of the research reported.

\section{Funding}

G Hilfenhaus was supported by a Gunther Speidel scholarship. C Fischer was supported by a grant from Experimental and Clinical Research Center, Berlin, Germany. This work was supported by a grant from Berliner Krebsgesellschaft e.V., Berlin, Germany.

\section{Acknowledgements}

We thank M Welzel for outstanding technical assistance, and R Pfragner and I Modlin for the opportunity to use the KRJ-I cells.

\section{References}

Alexandraki KI \& Kaltsas G 2012 Gastroenteropancreatic neuroendocrine tumors: new insights in the diagnosis and therapy. Endocrine 41 40-52. (doi:10.1007/s12020-011-9562-2)

Asada M, Ebihara S, Yamanda S, Niu K, Okazaki T, Sora I \& Arai H 2009 Depletion of serotonin and selective inhibition of $2 \mathrm{~B}$ receptor suppressed tumor angiogenesis by inhibiting endothelial nitric oxide synthase and extracellular signal-regulated kinase $1 / 2$ phosphorylation. Neoplasia $11408-417$.

Bagri A, Tessier-Lavigne M \& Watts RJ 2009 Neuropilins in tumor biology. Clinical Cancer Research 15 1860-1864. (doi:10.1158/1078-0432.CCR08-0563)

Bass MB, Sherman SI, Schlumberger MJ, Davis MT, Kivman L, Khoo HM, Notari KH, Peach M, Hei YJ \& Patterson SD 2010 Biomarkers as predictors of response to treatment with motesanib in patients with progressive advanced thyroid cancer. Journal of Clinical Endocrinology and Metabolism 95 5018-5027. (doi:10.1210/jc.2010-0947)

Batchelor TT, Sorensen AG, di Tomaso E, Zhang WT, Duda DG, Cohen KS, Kozak KR, Cahill DP, Chen PJ, Zhu M et al. 2007 AZD2171, a pan-VEGF receptor tyrosine kinase inhibitor, normalizes tumor vasculature and alleviates edema in glioblastoma patients. Cancer Cell 11 83-95. (doi:10.1016/j.ccr.2006.11.021)

Baudin E 2007 Gastroenteropancreatic endocrine tumors: clinical characterization before therapy. Nature Clinical Practice. Endocrinology \& Metabolism 3 228-239. (doi:10.1038/ncpendmet0425)

Carmeliet P, Moons L, Luttun A, Vincenti V, Compernolle V, De Mol M, Wu Y, Bono F, Devy L, Beck H et al. 2001 Synergism between vascular endothelial growth factor and placental growth factor contributes to angiogenesis and plasma extravasation in pathological conditions. Nature Medicine 7 575-583. (doi:10.1038/87904)

Cheng SJ, Lee JJ, Cheng SL, Chen HM, Chang HH, Wang YP, Kok SH, Kuo MY \& Chiang CP 2012 Increased serum placenta growth factor level is significantly associated with progression, recurrence and poor prognosis of oral squamous cell carcinoma. Oral Oncology 48 424-428. (doi:10.1016/j.oraloncology.2011.12.007)

Coenegrachts L, Maes C, Torrekens S, Van Looveren R, Mazzone M, Guise TA, Bouillon R, Stassen JM, Carmeliet P \& Carmeliet G 2010 Anti-placental growth factor reduces bone metastasis by blocking tumor cell engraftment and osteoclast differentiation. Cancer Research 70 6537-6547. (doi:10.1158/0008-5472.CAN-09-4092)

Corti A 2010 Chromogranin A and the tumor microenvironment. Cellular and Molecular Neurobiology 30 1163-1170. (doi:10.1007/s10571-0109587-8)

Couvelard A, O'Toole D, Turley H, Leek R, Sauvanet A, Degott C, Ruszniewski P, Belghiti J, Harris AL, Gatter K et al. 2005 Microvascular density and hypoxia-inducible factor pathway in pancreatic endocrine tumours: negative correlation of microvascular density and VEGF expression with tumour progression. British Journal of Cancer 92 94-101. (doi:10.1038/sj.bjc.6602245)

Detjen KM, Rieke S, Deters A, Schulz P, Rexin A, Vollmer S, Hauff P, Wiedenmann B, Pavel M \& Scholz A 2010 Angiopoietin-2 promotes disease progression of neuroendocrine tumors. Clinical Cancer Research 16 420-429. (doi:10.1158/1078-0432.CCR-09-1924)

Fan F, Samuel S, Gaur P, Lu J, Dallas NA, Xia L, Bose D, Ramachandran V \& Ellis LM 2011 Chronic exposure of colorectal cancer cells to bevacizumab promotes compensatory pathways that mediate tumour cell migration. British Journal of Cancer 104 1270-1277. (doi:10.1038/ bjc.2011.81)

Fischer C, Jonckx B, Mazzone M, Zacchigna S, Loges S, Pattarini L, Chorianopoulos E, Liesenborghs L, Koch M, De Mol M et al. 2007 Anti-PlGF inhibits growth of VEGF(R)-inhibitor-resistant tumors without affecting healthy vessels. Cell 131 463-475. (doi:10.1016/j.cell. 2007.08.038)

Fischer C, Mazzone M, Jonckx B \& Carmeliet P 2008 FLT1 and its ligands VEGFB and PIGF: drug targets for anti-angiogenic therapy? Nature Reviews. Cancer 8 942-956. (doi:10.1038/nrc2524)

de Groot JF, Piao Y, Tran HT, Gilbert MR, Wu HK, Liu J, Bekele BN, Cloughesy T, Mehta MP, Robins HI et al. 2011 Myeloid biomarkers associated with glioblastoma response to anti-vascular endothelial growth factor therapy with aflibercept. Clinical Cancer Research 17 4872-4881. (doi:10.1158/1078-0432.CCR-11-0271) 
Heindryckx F, Bogaerts E, Coulon SH, Devlies H, Geerts AM, Libbrecht L, Stassen JM, Carmeliet P, Colle IO \& Van Vlierberghe HR 2012 Inhibition of the placental growth factor decreases burden of cholangiocarcinoma and hepatocellular carcinoma in a transgenic mouse model. European Journal of Gastroenterology \& Hepatology 24 1020-1032. (doi:10.1097/MEG.0b013e3283554219)

Lassen U, Nielsen DL, Sorensen M, Winstedt L, Niskanen T, Stenberg Y, Pakola S, Stassen JM \& Glazer S 2012 A phase I, dose-escalation study of TB-403, a monoclonal antibody directed against PlGF, in patients with advanced solid tumours. British Journal of Cancer 106 678-684. (doi:10.1038/bjc.2011.609)

Lyden D, Hattori K, Dias S, Costa C, Blaikie P, Butros L, Chadburn A, Heissig B, Marks W, Witte L et al. 2001 Impaired recruitment of bone-marrow-derived endothelial and hematopoietic precursor cells blocks tumor angiogenesis and growth. Nature Medicine 7 1194-1201. (doi:10.1038/nm1101-1194)

Maae E, Olsen DA, Steffensen KD, Jakobsen EH, Brandslund I, Sorensen FB \& Jakobsen A 2012 Prognostic impact of placenta growth factor and vascular endothelial growth factor A in patients with breast cancer. Breast Cancer Research and Treatment 133 257-265. (doi:10.1007/ s10549-012-1957-0)

Marcellini M, De Luca N, Riccioni T, Ciucci A, Orecchia A, Lacal PM, Ruffini F, Pesce M, Cianfarani F, Zambruno G et al. 2006 Increased melanoma growth and metastasis spreading in mice overexpressing placenta growth factor. American Journal of Pathology 169 643-654. (doi:10.2353/ajpath.2006.051041)

Marion-Audibert AM, Barel C, Gouysse G, Dumortier J, Pilleul F, Pourreyron C, Hervieu V, Poncet G, Lombard-Bohas C, Chayvialle JA et al. 2003 Low microvessel density is an unfavorable histoprognostic factor in pancreatic endocrine tumors. Gastroenterology 125 1094-1104. (doi:10.1016/S0016-5085(03)01198-3)

von Marschall Z, Scholz A, Cramer T, Schafer G, Schirner M, Oberg K, Wiedenmann B, Hocker M \& Rosewicz S 2003 Effects of interferon alpha on vascular endothelial growth factor gene transcription and tumor angiogenesis. Journal of the National Cancer Institute 95 437-448. (doi:10.1093/jnci/95.6.437)

Martinsson-Niskanen T, Riisbro R, Larsson L, Winstedt L, Stenberg Y, Pakola S, Stassen JM \& Glazer S 2011 Monoclonal antibody TB-403: a first-in-human, phase i, double-blind, dose escalation study directed against placental growth factor in healthy male subjects. Clinical Therapeutics 33 1142-1149. (doi:10.1016/j.clinthera.2011.08.007)

Matsumoto K, Suzuki K, Koike H, Okamura K, Tsuchiya K, Uchida T, Takezawa Y, Kobayashi M \& Yamanaka H 2003 Prognostic significance of plasma placental growth factor levels in renal cell cancer: an association with clinical characteristics and vascular endothelial growth factor levels. Anticancer Research 23 4953-4958.

Modlin IM, Oberg K, Chung DC, Jensen RT, de Herder WW, Thakker RV, Caplin M, Delle Fave G, Kaltsas GA, Krenning EP et al. 2008 Gastroenteropancreatic neuroendocrine tumours. Lancet Oncology 9 61-72. (doi:10.1016/S1470-2045(07)70410-2)

Motzer RJ, Michaelson MD, Redman BG, Hudes GR, Wilding G, Figlin RA, Ginsberg MS, Kim ST, Baum CM, DePrimo SE et al. 2006 Activity of SU11248, a multitargeted inhibitor of vascular endothelial growth factor receptor and platelet-derived growth factor receptor, in patients with metastatic renal cell carcinoma. Journal of Clinical Oncology 24 16-24. (doi:10.1200/JCO.2005.02.2574)

Nagaoka S, Yoshida T, Akiyoshi J, Akiba J, Hisamoto T, Yoshida Y, Abe M, Koga H, Toirimura T, Ueno T et al. 2010 The ratio of serum placenta growth factor to soluble vascular endothelial growth factor receptor-1 predicts the prognosis of hepatocellular carcinoma. Oncology Reports 23 1647-1654. (doi:10.3892/or_00000807)

Nakamura T, Funayama H, Kubo N, Yasu T, Kawakami M, Momomura S \& Ishikawa SE 2009 Elevation of plasma placental growth factor in the patients with ischemic cardiomyopathy. International Journal of Cardiology 131 186-191. (doi:10.1016/j.ijcard.2007.10.050)
Paez-Ribes M, Allen E, Hudock J, Takeda T, Okuyama H, Vinals F, Inoue M, Bergers G, Hanahan D \& Casanovas O 2009 Antiangiogenic therapy elicits malignant progression of tumors to increased local invasion and distant metastasis. Cancer Cell 15 220-231. (doi:10.1016/j. ccr.2009.01.027)

Panzuto F, Boninsegna L, Fazio N, Campana D, Pia Brizzi M, Capurso G, Scarpa A, De Braud F, Dogliotti L, Tomassetti P et al. 2011 Metastatic and locally advanced pancreatic endocrine carcinomas: analysis of factors associated with disease progression. Journal of Clinical Oncology 29 2372-2377. (doi:10.1200/JCO.2010.33.0688)

Pape UF, Berndt U, Muller-Nordhorn J, Bohmig M, Roll S, Koch M, Willich SN \& Wiedenmann B 2008 Prognostic factors of long-term outcome in gastroenteropancreatic neuroendocrine tumours. Endocrine-Related Cancer 15 1083-1097. (doi:10.1677/ERC-08-0017)

Parr C, Watkins G, Boulton M, Cai J \& Jiang WG 2005 Placenta growth factor is over-expressed and has prognostic value in human breast cancer. European Journal of Cancer 41 2819-2827. (doi:10.1016/j.ejca. 2005.07.022)

Pavel ME, Hainsworth JD, Baudin E, Peeters M, Horsch D, Winkler RE, Klimovsky J, Lebwohl D, Jehl V, Wolin EM et al. 2011 Everolimus plus octreotide long-acting repeatable for the treatment of advanced neuroendocrine tumours associated with carcinoid syndrome (RADIANT-2): a randomised, placebo-controlled, phase 3 study. Lancet 378 2005-2012. (doi:10.1016/S0140-6736(11)61742-X)

Pfragner R, Wirnsberger G, Niederle B, Behmel A, Rinner I, Mandl A, Wawrina F, Luo J, Adamiker D, Hoger H et al. 1996 Establishment of a continuous cell line from a human carcinoid of the small intestine (KRJ-I). International Journal of Oncology 8 513-520.

Rahbari NN, Reissfelder C, Muhlbayer M, Weidmann K, Kahlert C, Buchler MW, Weitz J \& Koch M 2011 Correlation of circulating angiogenic factors with circulating tumor cells and disease recurrence in patients undergoing curative resection for colorectal liver metastases. Annals of Surgical Oncology 18 2182-2191. (doi:10.1245/ s10434-011-1761-9)

Raymond E, Dahan L, Raoul JL, Bang YJ, Borbath I, Lombard-Bohas C, Valle J, Metrakos P, Smith D, Vinik A et al. 2011 Sunitinib malate for the treatment of pancreatic neuroendocrine tumors. New England Journal of Medicine 364 501-513. (doi:10.1056/ NEJMoa1003825)

Rindi G, Kloppel G, Alhman H, Caplin M, Couvelard A, de Herder WW, Erikssson B, Falchetti A, Falconi M, Komminoth P et al. 2006 TNM staging of foregut (neuro)endocrine tumors: a consensus proposal including a grading system. Virchows Archiv 449 395-401. (doi:10.1007/s00428-006-0250-1)

Rindi G, Kloppel G, Couvelard A, Komminoth P, Korner M, Lopes JM, McNicol AM, Nilsson O, Perren A, Scarpa A et al. 2007 TNM staging of midgut and hindgut (neuro) endocrine tumors: a consensus proposal including a grading system. Virchows Archiv 451 757-762. (doi:10.1007/s00428-007-0452-1)

Rini BI, Michaelson MD, Rosenberg JE, Bukowski RM, Sosman JA, Stadler WM, Hutson TE, Margolin K, Harmon CS, DePrimo SE et al. 2008 Antitumor activity and biomarker analysis of sunitinib in patients with bevacizumab-refractory metastatic renal cell carcinoma. Journal of Clinical Oncology 26 3743-3748. (doi:10.1200/JCO.2007.15. 5416)

Schiettecatte J, Russcher H, Anckaert E, Mees M, Leeser B, Tirelli AS, Fiedler GM, Luthe H, Denk B \& Smitz J 2010 Multicenter evaluation of the first automated Elecsys sFlt-1 and PlGF assays in normal pregnancies and preeclampsia. Clinical Biochemistry 43 768-770. (doi:10.1016/j.clinbiochem.2010.02.010)

Schmidt T, Kharabi Masouleh B, Loges S, Cauwenberghs S, Fraisl P, Maes C, Jonckx B, De Keersmaecker K, Kleppe M, Tjwa M et al. 2011 Loss or inhibition of stromal-derived PIGF prolongs survival of mice with imatinib-resistant Bcr-Abl1(+) leukemia. Cancer Cell 19 740-753. (doi:10.1016/j.ccr.2011.05.007) 
Srirajaskanthan R, Dancey G, Hackshaw A, Luong T, Caplin ME \& Meyer T 2009 Circulating angiopoietin-2 is elevated in patients with neuroendocrine tumours and correlates with disease burden and prognosis. Endocrine-Related Cancer 16 967-976. (doi:10.1677/ERC09-0089)

Taylor AP, Leon E \& Goldenberg DM 2010 Placental growth factor (PlGF) enhances breast cancer cell motility by mobilising ERK1/2 phosphorylation and cytoskeletal rearrangement. British Journal of Cancer 103 82-89. (doi:10.1038/sj.bjc.6605746)

Terris B, Scoazec JY, Rubbia L, Bregeaud L, Pepper MS, Ruszniewski P, Belghiti J, Flejou J \& Degott C 1998 Expression of vascular endothelial growth factor in digestive neuroendocrine tumours. Histopathology 32 133-138. (doi:10.1046/j.1365-2559.1998.00321.x)

Van de Veire S, Stalmans I, Heindryckx F, Oura H, Tijeras-Raballand A, Schmidt T, Loges S, Albrecht I, Jonckx B, Vinckier S et al. 2010 Further pharmacological and genetic evidence for the efficacy of PlGF inhibition in cancer and eye disease. Cell 141 178-190. (doi:10.1016/j. cell.2010.02.039)

Verheul HM \& Pinedo HM 2007 Possible molecular mechanisms involved in the toxicity of angiogenesis inhibition. Nature Reviews. Cancer $\mathbf{7}$ 475-485. (doi:10.1038/nrc2152)

Wei SC, Tsao PN, Yu SC, Shun CT, Tsai-Wu JJ, Wu CH, Su YN, Hsieh FJ \& Wong JM 2005 Placenta growth factor expression is correlated with survival of patients with colorectal cancer. Gut $\mathbf{5 4} 666-672$. (doi:10.1136/gut.2004.050831)
Wei SC, Liang JT, Tsao PN, Hsieh FJ, Yu SC \& Wong JM 2009 Preoperative serum placenta growth factor level is a prognostic biomarker in colorectal cancer. Diseases of the Colon and Rectum 52 1630-1636. (doi:10.1007/DCR.0b013e3181afbdaf)

Willett CG, Duda DG, di Tomaso E, Boucher Y, Ancukiewicz M, Sahani DV, Lahdenranta J, Chung DC, Fischman AJ, Lauwers GY et al. 2009 Efficacy, safety, and biomarkers of neoadjuvant bevacizumab, radiation therapy, and fluorouracil in rectal cancer: a multidisciplinary phase II study. Journal of Clinical Oncology 27 3020-3026. (doi:10.1200/JCO. 2008.21.1771)

Yao J, Wu X, Zhuang G, Kasman IM, Vogt T, Phan V, Shibuya M, Ferrara N \& Bais C 2011a Expression of a functional VEGFR-1 in tumor cells is a major determinant of anti-PlGF antibodies efficacy. PNAS $\mathbf{1 0 8}$ 11590-11595. (doi:10.1073/pnas.1109029108)

Yao JC, Shah MH, Ito T, Bohas CL, Wolin EM, Van Cutsem E, Hobday TJ, Okusaka T, Capdevila J, de Vries EG et al. 2011b Everolimus for advanced pancreatic neuroendocrine tumors. New England Journal of Medicine 364 514-523. (doi:10.1056/ NEJMoa1009290)

Yao JC, Tsuchihashi Z, Panneerselvam A, Winkler RE, Bugarini R \& Pavel M 2011c 6573 POSTER Effect of everolimus treatment on markers of angiogenesis in patients with advanced pancreatic neuroendocrine tumours (pNET)-results from the phase III RADIANT-3 study. European Journal of Cancer $\mathbf{4 7}$ (Supplement 1) S463.

Received in final form 6 February 2013

Accepted 4 March 2013

Made available online as an Accepted Preprint

5 March 2013
(C) 2013 Society for Endocrinology Printed in Great Britain 